\title{
MRI examination teaching system by using virtual reality (VR)
}

\author{
Tzu-Chuen Lu ${ }^{1 *}$, Wei-Ying Li ${ }^{1}$, Ming-Rong You ${ }^{1}$, Clayton Chi-Chang \\ Chen $^{2,4}$, Jyh-Wen Chai ${ }^{3,4}$, Yi-Ying Wu ${ }^{4,5}$ \\ ${ }^{1}$ Department of Information Management, Chaoyang University of Technology, \\ Taichung, Taiwan \\ ${ }^{2}$ Department of Medical Education \& Radiology, Taichung Veterans General Hospital \\ Taichung, Taiwan \\ ${ }^{3}$ Department of Industrial Engineering and Enterprise Information, Tunghai \\ University, Taichung, Taiwan \\ ${ }^{4}$ College of Medicine, China Medical University, Taichung, Taiwan \\ ${ }^{5}$ Department of Electrical Engineering, National Chunghsing University, Taichung, \\ Taiwan
}

\section{OPEN ACCESS}

Received: November 1, 2020

Revised: June 3, 2021

Accepted: June 24, 2021

Corresponding Author:

Tzu-Chuen Lu

tclu@,cyut.edu.tw

Copyright: The Author(s). This is an open access article distributed under the terms of the Creative Commons Attribution License (CC BY 4.0), which permits unrestricted distribution provided the original author and source are cited.

\section{Publisher:}

Chaoyang University of

Technology

ISSN: 1727-2394 (Print)

ISSN: 1727-7841 (Online)

\begin{abstract}
This study proposes a magnetic resonance imaging (MRI) virtual reality system and uses a pulse oximeter measuring device to reduce patient's anxiety. The research investigates the radiation of the patient's heart rate when using the virtual reality system and degree of the individual's perception of anxiety. In the end, a questionnaire survey is conducted to understand the patient's views of this system.

This study uses Beckett Anxiety Scale to measure the degree of patient's anxiety. The experimental results show that the patient's anxiety level decreased from moderate anxiety to mild anxiety and the performance of heartbeat rate is very different between before and after using VR system. According to the results of the questionnaire, how easy the system is will affect the willing of the patient to use the system. Besides, the opinion of others will affect the patient's feeling of the useful of the system.
\end{abstract}

Keywords: Virtual reality, Anxiety testing, Anxiety beck inventory, Health education.

\section{INTRODUCTION}

Magnetic resonance imaging (MRI) is an item that can perform a full-body or partial physical examination (Peter, 2018). During the MRI test, the medical staff needs to let the patient understand the MRI operation status and notice before the examination. However, patients cannot rely on dictation to understand the actual MRI environment, and staff needs to repeatedly confirm or inform the notice again.

In order to reduce the waste of medical and human resources. This research developed an "MRI pre-testing and post-testing system platform for health education." The system uses video to increase the understanding of notice. To prevent patients from making mistakes during MRI examinations, we use the "3D virtual reality MRI health education system" that allows patients to experience the actual situation.

\section{RELATED WORKS}

The method of this research is combined with the hospital MRI process, and there is a screening mechanism before actually going through research process. In order to detect proper test subjects who might have anxiety symptoms, this research uses the Trait Anxiety Scale (TAS). The test patients are brought into the waiting room for one-by-one interviews. First, the study confirms that whether the patient is willing to participate in 
Lu et al., International Journal of Applied Science and Engineering, 18(5), 2020280

the research and let the patient fills out the consent form. After confirming that the patient has completed the consent form, the patient needs to fill the Pre-Beck Anxiety Inventory (PrBAI). Then, the patient wears the pulse oximeter monitoring, and then start to watch the health education video and answer patient-related questions for increasing the patient's understanding of the examination. After that, the study records the heart rate before using the system.

Then, the virtual reality experience is executed. During the experience, the variance of the heartbeat rate during used the virtual reality is recorded. After VR system, the patient fills the Post-Beck Anxiety Inventory (PoBAI). After the patient has performed the physical MRI examination, the patient will be asked to fill in the final system satisfaction questionnaire.

\subsection{The Trait Anxiety Scale (TAS)}

This study used the Trait Anxiety Scale (TAS) to confirm that each patient who was anxious. It is a measure used in many studies to explore the anxiety state of the patient. In this study, it is used to confirm whether the patient is suitable in this study.

The trait anxiety scale is an average score of 1.5 as judged by the physician and it shows anxiety, the person is suitable for using the system. The trait anxiety scale was compiled by Spielberg and Gosak in 1970 to measure personal general feelings.

\subsection{Anxiety Beck Inventory (ABI)}

This study used the Beckett Anxiety Scale (BAS) (Beck and Steer, 1990) to confirm the difference in anxiety between patients before and after used of virtual reality (Marilia, 2019), mainly to understand whether the patient's anxiety before the physical examination will be reduced by the use of virtual reality.

The Beck Anxiety Inventory (BAI) is a scale designed by Aaron Temkin Baker and his colleagues in 1988. It is hoped that the question items of the scale will be designed through various symptoms of anxiety, understand their anxiety status and they experienced in order to measure the anxiety status of most adults.

\subsection{Heart Rate Detector}

This study uses a pulse oximeter to understand whether there is a difference in the patient's heart rate before and after use of virtual reality. Before using virtual reality, patients will watch health education videos and collect the patient's normal heart rate during this period.

The heart rate data in the current situation is used to compare the heart rate difference in the virtual reality experience and after the experience. The method of heart rate monitoring has been used in many studies, such as understanding the patient's physical changes, and comparing whether the method or form used has an impact on the patient.

\subsection{Technology Acceptance Model}

This study uses technology acceptance model (TAM) to explore patient satisfaction after experiencing a virtual reality system. It is hoped that through the degree of acceptance of the system, the patient's perception of the system will be understood. TAM is a structural model developed by Davis based on theory of reasoned action (TRA) (Fishbein and Ajzen, 1977). The theory of rational behavior holds that human beings are very rational and logical in their use of any information system. Davis proposed TAM in 1989 to extend TRA's interpretation of the attitude and intention of using information systems (Fred, 1993). It increases the verification of the perceived usefulness (PU) of the cognitive system and the perceived ease of use (PEU) of whether the system is easy to use.

Venkatesh and Davis (2000) extended the TAM. As shown in Fig. 1, they added Social Influence (Subjective norm, Voluntariness, Image) and external perception (Job relevance, Output quality, Result demonstrability, Experience) to the original model to explain perceived usefulness and intention to use. It is found that social influence and external perception greatly affect user acceptance. The explanatory power for perceived usefulness is $40 \% \sim 60 \%$ and for intention to use is $34 \% \sim 52 \%$.

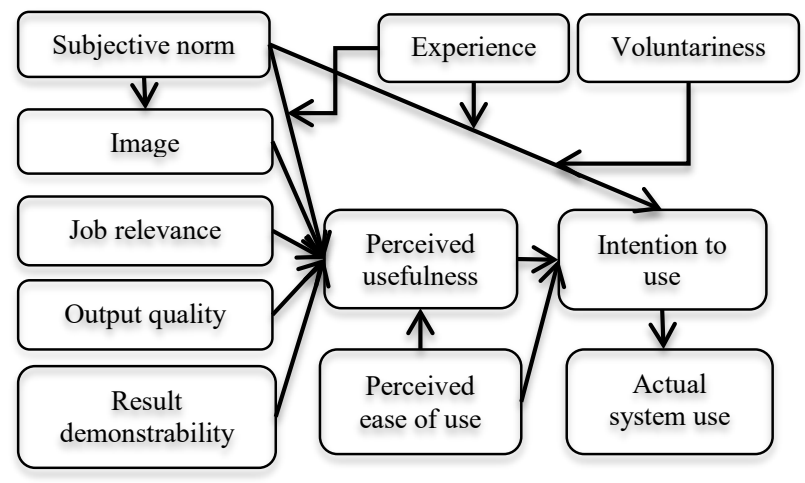

Fig. 1. Technology acceptance model 2

\subsection{Virtual Reality System and Video}

In the past research, it has been confirmed that virtual reality can cause acrophobia of patients in high-rise situations (Coelho et al., 1995). Therefore, a large number of acrophobia projects use virtual reality for treatment (Botella et al., 2000). For related fields, it has also been proved that virtual reality is more helpful and safer than the original treatment method (Alexander and Philip, 2019; Kumar and Arjen, 2019; Laura and Carly, 2019; Nexhmedin and Hiske, 2015).

This study developed a set of virtual reality and health education videos based on the hospital MRI process and put the two items into the examination process. The video can allow the patient to better understand inspection knowledge. The virtual reality is mainly used to let the patient understand the environment and process of the inspection. This reduces the anxiety that the patient may have during 


\section{International Journal of Applied Science and Engineering}

Lu et al., International Journal of Applied Science and Engineering, 18(5), 2020280

the examination. The screens of the VR system are shown in Fig. 2 and Fig. 3.

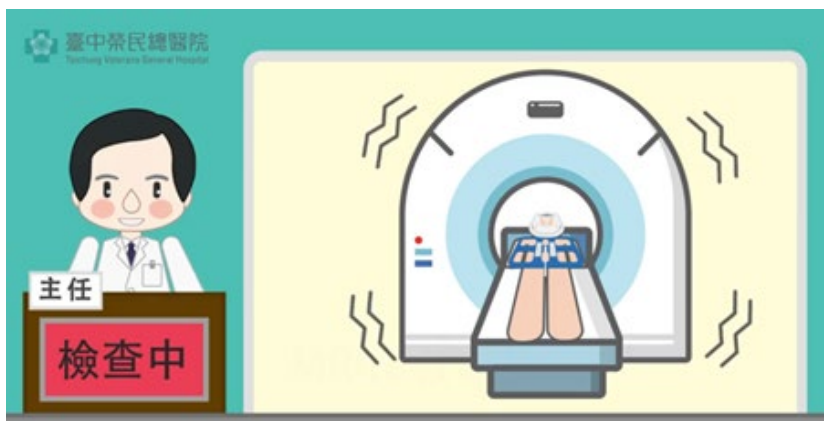

Fig. 2. The screen for MRI health education

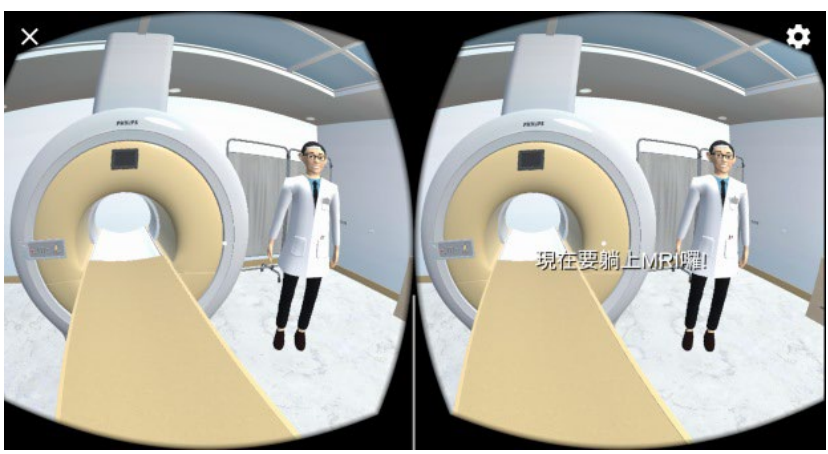

Fig. 3. The screen for MRI virtual reality

\section{RESULTS AND DISCUSSION}

This study conducted experiments in the Taichung veterans general hospital department of radiology from December 2019 to June 2020 and collected satisfaction questionnaires. Participants who first time performs MRI and pass test will be the test subjects. The total number of questionnaires was 48 . The surmised of the patients is shown in Table 1.
Table 1. Basic information of participants

\begin{tabular}{cccc}
\hline \multicolumn{2}{c}{ Items } & Quantity & $\%$ \\
\hline \multirow{2}{*}{ Gender } & male & 16 & $33 \%$ \\
& female & 32 & $67 \%$ \\
\hline \multirow{3}{*}{ Age } & under 18 & 1 & $3 \%$ \\
& $18 \sim 50$ & 14 & $29 \%$ \\
& over 50 & 33 & $68 \%$ \\
\hline \multirow{3}{*}{ Education } & primary school & 23 & $47 \%$ \\
& high school & 16 & $33 \%$ \\
\multirow{2}{*}{ Experience } & university & 9 & $20 \%$ \\
& yes & 14 & $30 \%$ \\
& no & 34 & $70 \%$ \\
\hline
\end{tabular}

\subsection{Heart Rate Detection}

In this study, the SPSS paired sample T-test was used to analyze the patient's heart rate before, during, and after used of virtual reality, for well know whether the use of virtual reality would affect the patient's feelings. As the results, there is a significant difference in heart rate before, during, and after use. The results are shown in Table 2.

The average heart rates of before, during and after using VR system are $76.62,82.79$ and 80.63 , respectively. The standard devious of before, during and after using VR system are $11.47,11.55$ and 12.84 .

\subsection{Beck Anxiety Inventory of the Experiments}

In this study, the SPSS paired sample T-test was used to test the beck anxiety inventory. Users were asked to fill in their anxiety before the test and compare their anxiety after using the virtual reality system to understand patient anxiety. Whether the situation is improved or not, the standard determination of the beck anxiety inventory depends on the standard used by Aaron Beck to compile the beck anxiety inventory. The standard of the beck anxiety inventory is shown in Table 3.

Table 2. Compare heart rate

\begin{tabular}{|c|c|c|c|c|c|c|c|}
\hline Stage & $\begin{array}{c}\text { Before } \\
\text { average }\end{array}$ & $\begin{array}{c}\text { During } \\
\text { average }\end{array}$ & $\begin{array}{c}\text { After } \\
\text { average }\end{array}$ & $\begin{array}{c}\text { Before } \\
\text { SD }\end{array}$ & $\begin{array}{c}\text { During } \\
\text { SD }\end{array}$ & $\begin{array}{c}\text { After } \\
\text { SD }\end{array}$ & $P$ value \\
\hline Before and during & \multirow{3}{*}{76.62} & \multirow{3}{*}{82.79} & \multirow{3}{*}{80.63} & \multirow{3}{*}{11.47} & \multirow{3}{*}{11.55} & \multirow{3}{*}{12.84} & 0.000 \\
\hline Before and after & & & & & & & 0.000 \\
\hline During and after & & & & & & & 0.001 \\
\hline
\end{tabular}

Table 3. Beck anxiety inventory standardized

\begin{tabular}{cc}
\hline \multicolumn{2}{c}{ Beck anxiety inventory } \\
\hline standardized & revel \\
\hline $0-7$ & Minimal \\
$8-15$ & Mild \\
$16-25$ & Moderate \\
$26-63$ & Severe \\
\hline
\end{tabular}




\section{International Journal of Applied Science and Engineering}

Lu et al., International Journal of Applied Science and Engineering, 18(5), 2020280

Table 4. Beck anxiety inventory result

\begin{tabular}{cccccc}
\hline Stage & before-Mean & after-Mean & before-SD & after-SD & P Value \\
\hline before and after & 23 & 8 & 7 & 2 & 0.000 \\
\hline
\end{tabular}

Experimental results show that the patient's anxiety was moderately anxious before using VR system. After using the virtual reality system, the anxiety state became slightly anxious. Through the results of the paired sample T-test, there is a significant difference between the before and after comparisons. The results is shown in Table 4.

\subsection{Validity and Reliability}

This study uses Partial Least Square to analyse the constructs to obtain the reliability and validity of each construct. Factor loading (FL) is 0.713 to 0.951 and average variance extracted (AVE) is 0.661 to 0.877 . The values greater than 0.5 indicate that the questionnaire has convergence validity. Construct reliability (CR) was 0.906 to 0.962 and the Cronbach's $\alpha$ was 0.870 to 0.951 . The values greater than 0.7 indicate that the questionnaire has reliability. The results are shown in Table 5 and Table 6 (Agarwal and Prasad, 1998; Davis et al., 1992; Hair et al., 2017).

Table 5. Descriptive statistics and factor loading

\begin{tabular}{cccc}
\hline Items & Mean & SD & Factor Loading \\
\hline PU 1 & 4.56 & 0.64 & 0.776 \\
PU 2 & 4.52 & 0.73 & 0.753 \\
PU 3 & 4.33 & 0.82 & 0.791 \\
PU 4 & 4.70 & 0.53 & 0.880 \\
PU 5 & 4.68 & 0.58 & 0.856 \\
\hline PEOU 1 & 4.66 & 0.62 & 0.888 \\
PEOU 2 & 4.79 & 0.49 & 0.885 \\
PEOU 3 & 4.72 & 0.48 & 0.902 \\
PEOU 4 & 4.68 & 0.50 & 0.798 \\
PEOU 5 & 4.70 & 0.53 & 0.713 \\
\hline BI 1 & 4.70 & 0.53 & 0.936 \\
BI 2 & 4.70 & 0.45 & 0.895 \\
BI 3 & 4.70 & 0.45 & 0.928 \\
BI 4 & 4.66 & 0.55 & 0.951 \\
BI 5 & 4.66 & 0.51 & 0.858 \\
\hline SI 1 & 4.54 & 0.64 & 0.954 \\
SI 2 & 4.54 & 0.57 & 0.937 \\
SI 3 & 4.58 & 0.60 & 0.917 \\
\hline
\end{tabular}

Table 6. Reliability and validity

\begin{tabular}{cccc}
\hline Item & Cronbach's $\alpha$ & CR & AVE \\
\hline PU & 0.870 & 0.906 & 0.661 \\
PEOU & 0.894 & 0.923 & 0.706 \\
BI & 0.951 & 0.962 & 0.836 \\
SI & 0.930 & 0.955 & 0.877 \\
\hline
\end{tabular}

\subsection{Path and Explanatory Power}

This study is to understand the degree of acceptance of the patients' using the VR system. The related effects of social influence, perceived usefulness, and perceived ease of use on intention to use were explored. The research model of the proposed scheme is shown in Fig. 4. related hypothesis are (Fred, 1993):

- H1: The user's perceived usefulness of the system will directly affect their intention to use.

- H2: When users use the system, they believe that the ease of use will affect the intention to use of the system.

- H3: When users use the system, they believe that the ease of use will affect the received usefulness of the system.

- H4: Important people around the user think that the user must use the system, which will affect the user's perceived usefulness of the system.

We analyze the impact between the constructs and determine whether the hypothesis is true or not. Fig. 4 shows the hypothesis verification results for $\mathrm{H} 1, \mathrm{H} 2, \mathrm{H} 3, \mathrm{H} 4$.

- H1: T statistics are 1.793 and $\mathrm{P}$ values are 0.073, indicating that it is non-significant. Perceived Usefulness has no effect on the intention to use. Therefore, $\mathrm{H} 1$ is rejected.

- H2: T statistics are 2.564 and P values are 0.010, indicating that it is significantly different. Perceived ease of use has an effect on the intention to use. Therefore, $\mathrm{H} 2$ is accepted.

- H3: T statistics are 4.599 and P values are 0.000, indicating that it is significantly different. Perceived ease of use has an effect on perceived usefulness. Therefore, $\mathrm{H} 3$ is accepted.

- H4: T statistics are 2.023 and P values are 0.043, indicating that it is significantly different. Social influence has an effect on perceived usefulness. Therefore, H4 is accepted.

\subsection{T-test and ANOVA}

Finally, this study used independent sample t-test and ANOVA analysis in SPSS to verify whether gender, age, and use experience would affect the results. As shown in Table 7 , the analysis result is that the p-value of gender for ease of use and willingness is less than 0.05 which indicates that the result is significant, and females are more affected. On the other hand, the p-value of age and use experience for any aspect is greater than 0.05 , which does not reach the significant standard. The results are shown in Table 8 and Table 9. 


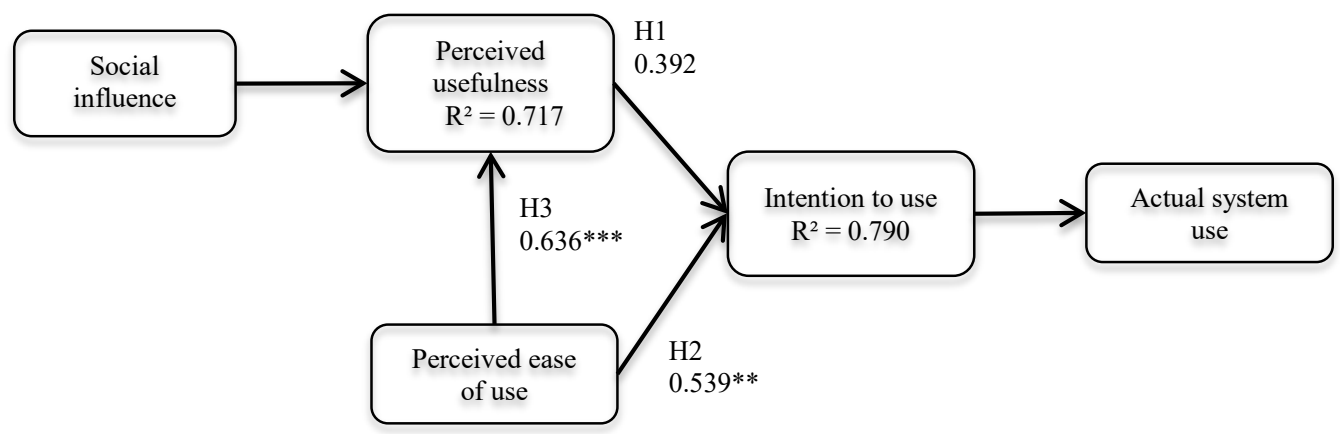

Fig. 4. Path Relationship of the proposed scheme

Table 7. Gender's mean of T-test

\begin{tabular}{ccccc}
\hline Item & male & female & $\mathrm{T}$ & $\mathrm{p}$ \\
\hline PU & 4.32 & 4.68 & -1.883 & 0.074 \\
PEOU & 4.47 & 4.83 & -2.256 & 0.037 \\
BI & 4.41 & 4.77 & -2.734 & 0.009 \\
SI & 4.33 & 4.66 & -1.943 & 0.058 \\
\hline
\end{tabular}

Table 8. Age's mean of ANOVA

\begin{tabular}{cccccc}
\hline Item & under 18 & $18 \sim 50$ & over 50 & $\mathrm{~F}$ & $\mathrm{p}$ \\
\hline PU & 4.20 & 4.58 & 4.56 & 0.229 & 0.796 \\
PEOU & 4.00 & 4.78 & 4.70 & 1.468 & 0.241 \\
BI & 4.00 & 4.70 & 4.65 & 1.103 & 0.341 \\
SI & 4.33 & 4.61 & 4.53 & 0.173 & 0.842 \\
\hline
\end{tabular}

Table 9. Experience's mean of T-test

\begin{tabular}{ccccc}
\hline Item & have experience & no have experience & $\mathrm{T}$ & $\mathrm{p}$ \\
\hline PU & 4.61 & 4.54 & 0.421 & 0.676 \\
PEOU & 4.81 & 4.67 & 0.964 & 0.340 \\
BI & 4.77 & 4.60 & 1.307 & 0.200 \\
SI & 4.64 & 4.51 & 0.669 & 0.507 \\
\hline
\end{tabular}

\section{CONCLUSION}

In order to let patients can understand the environment, process, and notification of MRI examination and reduce anxiety, this study develops a $3 \mathrm{D}$ virtual reality system. The system simulates the complete inspection process and allows patients to understand all inspection precautions through the videos and games. From the results of beck anxiety inventory, the state of patient's anxiety from middle to low after watching videos and using VR system. The results show that the knowledge of MRI can reduce the anxiety. The heart rate records are used to the reaction of patients. This study comprised the heart rates of before, during, and after of using VR system. The results show the patient's heart rate of before used VR is significantly different from that of during and after using VR. Numerically, it can be observed that the difference between before and during used of the virtual reality system is significant, that means the developed system does change the patient's heart rate.
According to the results of the questionnaire survey, the average value of each question is $3 \sim 5$, which means the patient's satisfaction with the system is acceptable. The reliability and validity meet the measurement standards that indicates the questionnaire is correct. In the path analysis part, H2, H3, and $\mathrm{H} 4$ reached a significant difference that means the hypothesis are correct. H1 did not reach a significant difference that means this hypothesis may not be so meaningful in the questionnaire this time. The analysis results of $\mathrm{H} 2, \mathrm{H} 3$, and $\mathrm{H} 4$ show that when using the system, the patient feels the system is easy to use. Because the system is easy to use, it affects the patient's intention to use the system. The ease of use of the system also affects the patient's use of the system, and social influence will affect the patient's perceived usefulness. But $\mathrm{H} 1$ also shows that although the patient feels this system is useful, it will not affect the patient's willingness to use it.

During the execution of the process, this study asked the patients some things about the system that can be improved. Some patients pointed out that there is still has room for improvement in the environmental simulation. Many 
problems with the screen display need to be improved. The reason is that during the process, the patient wore a VR helmet to walk, which caused the patient to feel dizzy. If the patient watches the VR video in a fix place or lying on the bed, then the feeling of dizziness can be avoided. These problems can be corrected in the future, such that help the patients has authentic experience.

\section{ACKNOWLEDGMENT}

This research would like to thank the support of Chaoyang University of Technology and Taichung Veterans General Hospital Tcvghcyut1088801 and the partial funding of Ministry of Education, Taiwan Most 109-2221-E-324025-1443.

\section{REFERENCES}

Agarwal, R., Prasad, J. 1998. A conceptual and operational definition of personal innovativeness in the domain of information technology, Information Systems Research, 9, 204-215.

Alexander, M., Philip, L. 2019. Automated virtual reality exposure therapy for spider phobia vs. in-vivo onesession treatment: A randomized non-inferiority trial, Behaviour Research and Therapy, 118, 130-140.

Beck, A.T., Steer, R.A. 1990. Manual for the beck anxiety inventory, Psychological Corporation.

Botella, C., Banos, R.M., Villa, H., Perpina C., GarciaPalacios, A. 2000. Virtual reality in the treatment of claustrophoibc fear: A controlled, Multiple-baseline design, Behavior Therapy, 31, 583-595.

Coelho, C.M., Waters, A., Hine, T.J., Wallis, G. 1995. The use of virtual reality in acrophobia research and treatment, Journal of Anxiety Disorders, 23, 563-574.

Davis, F.D., Bagozzi, R.P., Warshaw, P.R. 1992. Extrinsic and intrinsic motivation to use computers in the workplace, Journal of Applied Social Psychology, 22, 1111-1132.

Fishbein, M., Ajzen, I. 1977. Belief, attitude, intention, and behaviour: An introduction to theory and research.

Fred, D.D. 1993. User acceptance of information technology: system characteristics, user perceptions, and behavioural impacts, International Journal of ManMachine Studies, 38, 475-487.

Hair, J.F., Hult, G.T.M., Ringle, C.M., Sarstedt, M. 2017. A primer on partial least squares structural equation modelling (PLS-SEM), Sage, Thousand Oaks, CA.

Kumar, R.G., Arjen, V.W. 2019. Efficacy of virtual reality exposure therapy for the treatment of dental phobia in adults: A randomized controlled trial, Journal of Anxiety Disorders, 62, 100-108.

Laura, L., Carly, Y. 2019. You can do that?!: Feasibility of virtual reality exposure therapy in the treatment of PTSD due to military sexual trauma, Journal of Anxiety Disorders, 61, 55-63.
Peter, A.R. 2018. Magnetic resonance in medicine, A critical introduction. The Basic Textbook of the European Magnetic Resonance Forum.

Marilia, F.L. 2019. Preoperative education reduces preoperative anxiety in cancer patients undergoing surgery: usefulness of the self-reported beck anxiety inventory, Brazilian Journal of Anaesthesiology, 69, 1-6.

Nexhmedin, M., Hiske, I. 2015. Can virtual reality exposure therapy gains be generalized to real-life? A meta-analysis of studies applying behavioral assessments, Behaviour Research and Therapy, 74, 18-24.

Venkatesh, V., Davis, F.D. 2000. A theoretical extension of the technology acceptance model: four longitudinal field studies, Management Science, 46, 186-204. 